\title{
Prevalence of gender based violence and associated factors among female students of Menkorer high school in Debre Markos town, Northwest Ethiopia
}

\author{
Getachew Mullu" ", Ayu Gizachew ${ }^{1}$, Desalegne Amare², Animut Alebel², Fasil Wagnew², \\ Chalachew Tiruneh ${ }^{2}$, Mulat Worku ${ }^{2}$, Rhama Kediri ${ }^{2}$, Sanbato Tamiru ${ }^{2}$, Temesgen Demsie ${ }^{2}$ \\ ${ }^{1}$ Midwifery department, College of Medicine and Health Science, Debre Markos University, Debre Marko, Ethiopia \\ ${ }^{2}$ Nursing department, College of Medicine and Health Science, Debre Markos University, Debre Markos, Ethiopia
}

\section{Email address:}

gechm2005@gmail.com (G. Mullu), ayugizachew@yahoo.com (A. Gizachew),desa2001@yahoo.com (D. Amare), animut.a23@gmail.com (A. Alebel), fasil.n@gmail.com (F. Wagnew), chaletiruneh@yahoo.com (C. Tiruneh), mulat.worku@yahoo.com (M. Worku),rhama.13@gmail.com (R. Kedir), tsanbato@yahoo.com (S. Tamiru), dtemesgen@yahoo.com (T. Demise)

\section{To cite this article:}

Getachew Mullu, Ayu Gizachew, Desalegne Amare, Animut Alebel, Fasil Wagnew, Chalachew Tiruneh, Mulat Worku, Rhama Kediri, Sanbato Tamiru, Temesgen Demsie. Prevalence of Gender Based Violence and Associated Factors among Female Students of Menkorer High School in Debre Markos Town, Northwest Ethiopia. Science Journal of Public Health. Vol. 3, No. 1, 2015, pp. 67-74. doi: $10.11648 /$ j.sjph.20150301.22

\begin{abstract}
Introduction: Gender based violence (GBV) is a common reproductive health problem especially in developing countries. It commonly occurs among women and young girls than men, and it has several sexual and reproductive health complications like STIs including HIV/AIDS, unwanted pregnancy, abortion and other complications. So, this research is done to assess the prevalence of GBV and associated factors among Menkorer high school female students in Debre Markos town, Ethiopia. Methodology: Institutional based cross sectional study was conducted among 140 female high school students of Debre Markos town. All randomly selected regular female students were included in the study. Self-administered questionnaire was used to collect the data. For data entry EpiData version 3.1 and for analysis SPSS version 22 software were used. Descriptive analysis was done to describe the frequency and percentage of dependent and independent variables. To identify possible factors associated with the dependent variable, bivariate and multivariate analysis were done. $95 \%$ confidence interval (CI) and p-value less than 5\% were used to determine the association. Result: The prevalence of Gender based violence (physical or/and sexual violence) during the current academic year was 72 (57.3\%), while life time prevalence of GBV was $67.7 \%$. The prevalence of life time physical violence and physical violence during the current academic year was $82(66.1 \%)$ and $68(54.8 \%)$ respectively. Thirty (24.2\%) have experience life time sexual violence. Factors associated with gender based violence were educational performance of good and above ( $\mathrm{AOR}=0.09,95 \% \mathrm{CI} 0.009-0.88$ ), and never drinking alcohol (AOR $=0.38,95 \% \mathrm{CI} 0.15-0.93$ ). Conclusion and Recommendation: This study found that gender based violence is still a common problem among high school female students. The prevalence of current and life time physical and sexual violence among female students was high. So, school and community based services like awareness creation for both male and female students on GBV and laws related with GBV should be strengthened.
\end{abstract}

Keywords: Gender Based Violence, Physical Violence, Sexual Violence, Female Students, Ethiopia

\section{Introduction}

Gender based violence (GBV) is common in several communities around the world, and exposure to GBV increases risk of complication related with non-use of condom, like HIV/AIDS, unwanted and early pregnancy and its complications (1).

GBV is a human right violation, and is one of the constraint for gender equality and development for the nation. Even if it affects both men and women, it is more common among women and girls $(2,3)$.

GBV results in physical injuries and chronic infections, and several poor sexual and reproductive health outcomes.(1) 
For example studies showed that women who experienced violence are more likely to develop sexual transmitted infections (STIs) including HIV infection, unwanted pregnancy and unsafe abortion $(1,4)$. Generally GBV affects the physical, mental and social well-being of women and girls (2).

A study conducted among female University Students in Northern Nigeria showed that the prevalence of GBV was $58.8 \%$. From these, $22.8 \%$ experienced physical violence, $22.2 \%$ sexual violence and $50.8 \%$ experienced emotional and verbal violence (5).

A study conducted on sexual violence among female high school students in Debarik also showed that sexual violence is still a common phenomenon among young girls. The study showed that the prevalence of performed and attempted rape was $8.8 \%$ and $11.5 \%$. In addition the common complications due to rape were pregnancy, suicidal attempt, vaginal discharge and abortion (6).

So, this research was conducted to assess the prevalence of Gender based violence and its associated factors among female students of Menkorer high school at Debre Markos town.

\section{Methodology}

\subsection{Study Area and Period}

This study was conducted in Menkorer high school, which is found in Debre Markos town, East Gojjam zone. Debre Markos town is located $299 \mathrm{~km}$ north west from Addis Ababa and $255 \mathrm{~km}$ East from Bahirdar, capital city of Amhara region. According to 2007 national census reports, Debre Markos town has a total population of 62,497 , of which 32 , 576 are women and 29,921 are men. About $97 \%$ of the population said they follow Orthodox Christianity religion. In addition the largest ethnicity in the town was Amhara accounting $97.12 \%$ (7). Menkorer high school has a total of 1082 students from which 639 are female students. Data was collected from April 16-18, 2014.

\subsection{Study Design, Population and Study Variables}

Institutional based cross sectional study design was conducted. The source populations of this study were all female students at Menkorer high school of Debre Markos town. All randomly selected regular female students were included in the study. Non regular female and Student who are seriously ill during the data collection period were excluded from the study. The dependent variable of this study was Gender based violence, and the independent variables were: the socio demographic characteristics, parental characteristics, personal behavior of respondents, and sexual history of respondents.

\subsection{Sample Size and Sampling Procedure}

Single population proportion and adjusting formula was used to determine the sample size. By considering prevalence GBV/attempted rape of $11.5 \%$ obtained from a study among
Debark high school students (8), 95\% CI, 5\% margin of error and $10 \%$ non-response rate. The final sample size was 140 female students. Stratified sampling technique was used to select the study participants. List of female students in grade 9 and 10 was obtained from the registrar office of the school. Then simple random sampling method was used to select the participants (Figure 1).

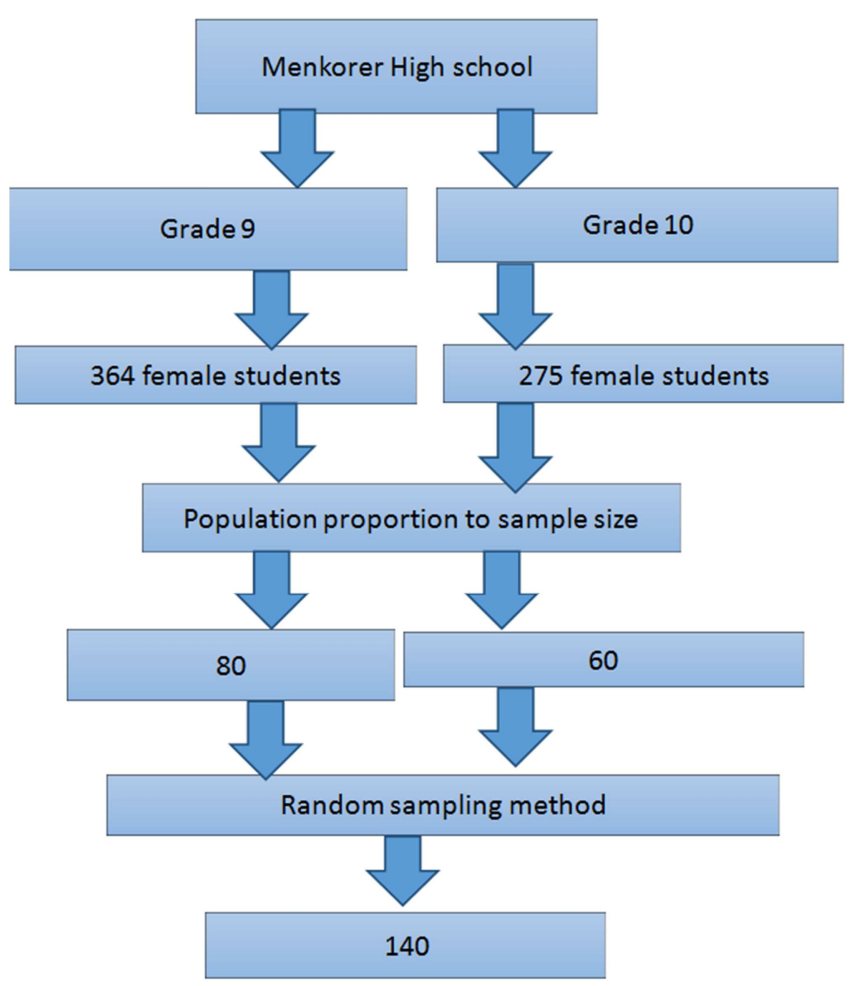

Figure 1. Schematic presentation of the sampling procedure.

\subsection{Data Collection and Analysis}

Self-administered questionnaire was used to collect the data. The questionnaire was adapted from a similar study done in northern Ethiopia (9). The data collection instrument was first prepared in English and then translated to Amharic by individual who have good knowledge of both languages.

The collected data was entered to EpiData version 3.1 and then exported to SPSS version 22 for further analysis. Descriptive analysis was done to describe the frequency and percentage of dependent and independent variables. To identify possible factors associated with the dependent variable, bivariate and multivariate analysis were done. In addition 95\% confidence interval $(\mathrm{CI})$ and $\mathrm{p}$-value less than $5 \%$ were used to determine the association.

\subsection{Ethical Consideration}

Ethical clearance was obtained from Debre Markos University, College of medicine and health science. Permission was obtained from Menkorer high school administration office, the purpose and significance of the study was also described to the study subjects, and study participants were informed as their information will be kept confidentially. 


\section{Result}

\subsection{Socio Demographic Characteristics}

Out of 140 female students, 124 completed the questionnaire giving a response rate of $88.6 \%$. Majority, 82 $(66.1 \%)$ of respondents were in the age group of 17 to 19 years old. The mean and standard deviation for age of respondents were 17.2 and 1. 6 years respectively. Most, $73.4 \%$ of respondents were orthodox religion followers. Respondents with previous residence of rural area were 53(42.7\%), and urban were $71(57.3 \%)$. Twenty $(16.1 \%)$ of respondents said that their current educational status were good and above, followed by average $(72.6 \%) \&$ poor $(11.3 \%)$ (Table 1$)$.

Sixty two $(50 \%)$ of respondents mother were with educational status of grade 1 to 8 , and similarly $46(37.1 \%)$ of respondents father were with educational status of grade 1 to 8 . According to respondents response, $50(40.3 \%)$ said that their perceived family income was better, $51(41.1 \%)$ average and $23(18.5 \%)$ poor. In addition $58(46.8 \%)$ of respondents said that they have witnessed violence as a child, while 66 $(53.2 \%)$ said that they didn't. More than two third, (68.5\%) of respondents said that there is no free discussion with their family members on several issues, while 39(31.5\%) said they freely discuss with their family.

Regarding the substance abuse, 84 (67.7\%), 114 (91.9\%), and 119 (96\%) had never drunk, never chewed chat and never smoked cigarette respectively. In addition 24 (19.4\%) said that they have a close friend who drinks alcohol.

Thirty two $(25.8 \%)$ of respondents said that they had sexual intercourse. From those respondents who start sexual intercourse, $18(56.2 \%)$ and $14(43.8 \%)$ said that the age at first sex was less than 18 and greater than 18 years old respectively. The mean age at first sexual intercourse was 16.2 years old with SD of 1.6 years and minimum and maximum age of 12 and 19 years respectively. Only $8(25 \%)$ of respondents who start sex were willing during the first sexual intercourse, while $24(75 \%)$ were unwilling at first sex. Half $(50 \%)$ of respondents who start sex had multiple (more than 2) life time sexual partners. And 7 (21.9\%) of respondents who start sex also said that they have more than one sexual partner currently.

Table 1. Socio demographic characteristics of Menkorer high school female students, Debre Markos town, North West Ethiopia, 2014/15.

\begin{tabular}{|c|c|c|c|}
\hline Variable & & Frequency & Percentage \\
\hline Age & $14-16$ years old & 35 & 28.2 \\
\hline Mean $=17.2$ years & 17-19 years old & 82 & 66.1 \\
\hline $\mathrm{SD}=1.6$ years & 20-23 years old & 7 & 5.6 \\
\hline \multirow{3}{*}{ Religion } & Orthodox & 91 & 73.4 \\
\hline & Protestant & 9 & 7.3 \\
\hline & Muslim & 24 & 19.4 \\
\hline Educational level & Grade 10 & 54 & 43.5 \\
\hline \multirow{5}{*}{ Previous semester average result } & $90-100$ & 3 & 2.4 \\
\hline & $80-89$ & 42 & 33.9 \\
\hline & $70-79$ & 53 & 42.7 \\
\hline & $50-69$ & 25 & 20.2 \\
\hline & Less than 50 & 1 & 0.8 \\
\hline \multirow[t]{2}{*}{ Current Educational status/performance } & Average & 90 & 72.6 \\
\hline & Poor & 14 & 11.3 \\
\hline \multirow{2}{*}{ Previous residence } & Rural & 53 & 42.7 \\
\hline & Urban & 71 & 57.3 \\
\hline \multirow{3}{*}{ Living condition } & Alone & 13 & 10.5 \\
\hline & With family/relatives/husband & 102 & 82.3 \\
\hline & With friends & 9 & 7.3 \\
\hline \multirow{2}{*}{ Pocket money } & Yes & 90 & 72.6 \\
\hline & No & 34 & 27.4 \\
\hline
\end{tabular}

\subsection{Physical Violence}

Physical violence was assessed before joining high school, since joining high school and in the current academic year. As presented in table 2, the prevalence of life time physical violence and physical violence during the current academic year was $82(66.1 \%)$ and $68(54.8 \%)$ respectively. In addition $79(63.7 \%)$ of respondents said that they have experienced any form of physical violence before joining high school and $45(36.3 \%)$ didn't experience any form of physical violence before joining high school. More than half, 53.2\%, of respondents also said that they have experienced any form of physical violence since joining high school.

Family members, 39 (47.6\%) and students, 28 (34.5\%) were the common source of physical violence among the respondent. Others also include teachers, 17 (20.7\%); strangers 14 (17.1\%); and boyfriend/ or husband, $13(15.9 \%)$.

Respondents have also reported regarding the consequences of physical violence. Accordingly, the common types of physical violence reported were disgusting people, 
poor school achievement, school failure, withdrawal from school, temporary body injury, and sustained disability accounting 33 (40\%), 24 (29.3\%), 12 (14.6\%), 12 (14.6\%), 6 $(7.3 \%)$, and $1(1.2 \%)$ respectively.

Table 2. Distribution of types of physical violence among female students of Menkorer high school, Debre Markos, town, East Gojjam zone, Ethiopia.

\begin{tabular}{|c|c|c|c|c|}
\hline Variable & & Before joining high school & Since joining high school & This year $(2013 / 14)$ \\
\hline \multirow{2}{*}{$\begin{array}{l}\text { Ever been slapped/ or thrown something } \\
\text { at you that could help you }\end{array}$} & Yes $n(\%)$ & $57(46 \%)$ & $43(34.7 \%)$ & $41(33.1 \%)$ \\
\hline & No $n(\%)$ & $67(54 \%)$ & $81(65.3 \%)$ & $83(66.9 \%)$ \\
\hline \multirow{2}{*}{ Ever been pushed/shoved } & Yes $n(\%)$ & $49(39.5 \%)$ & $46(37.1 \%)$ & $44(35.5 \%)$ \\
\hline & No $n(\%)$ & $75(60.5 \%)$ & $78(62.9 \%)$ & $80(64.5 \%)$ \\
\hline \multirow{2}{*}{ Ever beaten with fist } & Yes n $(\%)$ & $39(31.5 \%)$ & $29(23.4 \%)$ & $26(21 \%)$ \\
\hline & No n $(\%)$ & $85(68.5 \%)$ & $95(76.6 \%)$ & $98(79 \%)$ \\
\hline Ever been kicked & Yes n $(\%)$ & $44(35.5)$ & $31(25)$ & $28(22.6)$ \\
\hline \multirow{2}{*}{ Ever been chocked purposely } & Yes $n(\%)$ & $25(20.2)$ & $14(11.3)$ & $10(8.1)$ \\
\hline & No $n(\%)$ & $99(79.8)$ & $110(88.7)$ & 114(91.9) \\
\hline \multirow{2}{*}{$\begin{array}{l}\text { Ever been threatened verbally/ or gun/ } \\
\text { or knife }\end{array}$} & Yes $n(\%)$ & $17(13.7)$ & $19(15.3)$ & $20(16.1)$ \\
\hline & No $n(\%)$ & $107(86.3)$ & $105(84.7)$ & $104(83.9)$ \\
\hline \multirow{2}{*}{ Any type of physical violence this year } & Yes & $68(54.8)$ & & \\
\hline & No & $56(45.2)$ & & \\
\hline $\begin{array}{l}\text { Any type of physical violence before } \\
\text { joining high school }\end{array}$ & Yes & $79(63.7)$ & & \\
\hline \multirow{2}{*}{$\begin{array}{l}\text { Any type of physical violence since } \\
\text { joining high school }\end{array}$} & Yes & $66(53.2)$ & & \\
\hline & No & $58(46.8)$ & & \\
\hline \multirow{2}{*}{ Life time physical violence } & Yes & $82(66.1)$ & & \\
\hline & No & $42(33.9)$ & & \\
\hline
\end{tabular}

\subsection{Factors Associated with Physical Violence}

The bivariate analysis and multivariate analysis was computed to determine possible association between the independent variables with physical violence during the current year (2014/15). In bivariate analysis factors found to be associate with the dependent variable were; current educational status of good and above $(\mathrm{COR}=0.12,95 \% \mathrm{CI} 0.02-0.58)$, witness of violence as a child $(\mathrm{COR}=2.3,95 \% \mathrm{CI} 1.1-4.72)$,
Alcohol drinking $(\mathrm{COR}=3.96,95 \%$ CI 1.37-11.42), Having a friend who drink alcohol $(\mathrm{COR}=3,95 \% \mathrm{CI} 1.1-8.19)$ and ever having sexual intercourse $(\mathrm{COR}=3.27,95 \% \mathrm{CI} 1.33-8.04)$. Candidate variables with p- value of less than $20 \%$ were selected and entered to multivariate analysis to determine the association. Accordingly variables like urban residence $(\mathrm{AOR}=$ $4.85,95 \%$ CI 1.06-22.19), and witness of violence as a child (AOR 3.7, 95\% CI 1.05-12.91) (Table 3).

Table 3. Bivariate and multivariate regression analysis for factors associated with physical violence in the current year among female students of Menkorer high school in Debre Markos town, Northwest Ethiopia, 2014.

\begin{tabular}{|c|c|c|c|c|c|c|}
\hline \multirow{2}{*}{ Variables } & & \multicolumn{2}{|c|}{ Physical violence } & \multirow{2}{*}{$\operatorname{COR}(95 \% \mathrm{CI})$} & \multirow{2}{*}{$\operatorname{AOR}(95 \% \mathrm{CI})$} & \multirow{2}{*}{ P-value } \\
\hline & & No & Yes & & & \\
\hline \multirow{3}{*}{$\begin{array}{l}\text { Current Educational } \\
\text { status }\end{array}$} & Good \& above & $14(70)$ & $6(30)$ & $0.12(0.02,0.58)$ & $0.16(0.01,2.21)$ & 0.172 \\
\hline & Average & $39(43.3)$ & $51(56.7)$ & $0.36(0.09,1.37)$ & $1.06(0.15,7.28)$ & 0.957 \\
\hline & Poor & $3(21.4)$ & $11(78.6)$ & 1 & 1 & \\
\hline \multirow{2}{*}{ Residence } & Rural & $22(41.5)$ & $31(58.5)$ & 1 & 1 & \\
\hline & Urban & $34(47.9)$ & $37(52.1)$ & $0.77(0.38,1.58)$ & $4.85(1.06,22.19)$ & 0.042 \\
\hline \multirow{2}{*}{$\begin{array}{l}\text { Witness of violence as } \\
\text { a child }\end{array}$} & Yes & $20(34.5)$ & $38(65.5)$ & $2.3(1.1,4.72)$ & $3.7(1.05,12.91)$ & 0.041 \\
\hline & No & $36(54.5)$ & $30(45.5)$ & 1 & 1 & \\
\hline \multirow{2}{*}{ Alcohol drinking } & Ever drunk & $14(35)$ & $26(65)$ & $3.96(1.37,11.42)$ & $0.49(0.1,2.34)$ & 0.375 \\
\hline & Never drunk & $42(50)$ & $42(50)$ & 1 & 1 & \\
\hline \multirow{2}{*}{$\begin{array}{l}\text { Have a friend who } \\
\text { drink alcohol }\end{array}$} & Yes & $6(25)$ & $18(75)$ & $3(1.1,8.19)$ & $8.45(0.77,92.53)$ & 0.081 \\
\hline & No & $50(50)$ & $50(50)$ & 1 & 1 & \\
\hline \multirow[t]{2}{*}{ Ever had sex } & Yes & $8(25)$ & $24(75)$ & $3.27(1.33,8.04)$ & $3.37(0.46,24.68)$ & 0.232 \\
\hline & No & $48(52.2)$ & $44(47.8)$ & 1 & 1 & \\
\hline
\end{tabular}

\subsection{Sexual Violence}

Regarding sexual violence, $36(29 \%)$ of respondents had faced unwelcomed touch, $25(20.2 \%)$ forced to have sex that they have escaped, and $16(12.9 \%)$ had experienced forceful sexual intercourse. Thirty $(24.2 \%)$ have experience life time sexual violence, while $94(75.8 \%)$ of respondents had never experienced sexual violence in their time (Table 4).
Respondents also said that they have faced several consequences due to the sexual violence. These complications include; injury around the genitalia $10(33.3 \%)$, unusual vaginal bleeding $6(20 \%)$, pregnancy $5(16.7 \%)$, swelling around genitalia $4(13.3 \%)$, and abortion $1(3.3 \%)$. Psychological consequences experienced due to forced sex were; fear $20(66.7 \%)$, anxiety $19(63.3 \%)$, depression 19 $(63.3 \%)$, hopelessness $9(30 \%)$, self-blame $6(20 \%)$ and 
suicidal attempt $2(6.7 \%)$. Social consequences and risky sexual behaviors due to forced sex also include; withdrawal from school $19(63.3 \%)$, poor academic achievement 16
$(53.3 \%)$, rejection from friends $9(30 \%)$, rejection from family $3(10 \%)$, alcohol dependency $2(6.7 \%)$ and sexual dependency 1 (3.3\%) (Table 5).

Table 4. Distribution of sexual violence among female students of Menkorer high school, Debre Markos, town, East Gojjam zone, Ethiopia.

\begin{tabular}{|c|c|c|c|c|}
\hline Variable & & Before joining high school & Since joining high school & This year $(2013 / 14)$ \\
\hline \multirow{2}{*}{ Ever been faced unwelcome touch sexually } & Yes $n(\%)$ & $26(21)$ & $37(29.8)$ & $36(29)$ \\
\hline & No $n(\%)$ & $98(79)$ & $87(70.2)$ & $88(71)$ \\
\hline \multirow{2}{*}{ Ever been forced to have sex that you have escaped } & Yes n $(\%)$ & $35(28.2)$ & $27(21.8)$ & $25(20.2)$ \\
\hline & No n $(\%)$ & $89(71.8)$ & $97(78.2)$ & $99(79.8)$ \\
\hline \multirow{2}{*}{ Ever been had sexual intercourse forcefully } & Yes n $(\%)$ & $24(19.4)$ & $16(12.9)$ & $16(12.9)$ \\
\hline & No $n(\%)$ & $100(80.6)$ & $108(87.1)$ & $108(87.1)$ \\
\hline Life time sexual violence & Yes & $30(24.2)$ & & \\
\hline
\end{tabular}

Table 5. Consequences of sexual violence among female students of Menkorer high school, Debre Markos, town, East Gojjam zone, Ethiopia.

\begin{tabular}{|c|c|c|c|}
\hline Variable & & Frequency & Percentage \\
\hline \multirow{5}{*}{ Physical consequence of forced sex * } & Unusual vaginal discharge & 6 & 20 \\
\hline & Swelling around the genitalia & 4 & 13.3 \\
\hline & Injury around the genitalia & 10 & 33.3 \\
\hline & Pregnancy & 5 & 16.7 \\
\hline & Abortion & 1 & 3.3 \\
\hline \multirow{5}{*}{ Psychological consequence experienced due to forced sex * } & Self-blame & 6 & 20 \\
\hline & Fear & 20 & 66.7 \\
\hline & Hopelessness & 9 & 30 \\
\hline & Depression & 19 & 63.3 \\
\hline & Suicidal attempt & 2 & 6.7 \\
\hline \multirow{5}{*}{ Social consequences and risky behaviors due to forced sex * } & Poor academic achievement & 16 & 53.3 \\
\hline & Withdrawal & 19 & 63.3 \\
\hline & Rejection from family & 3 & 10 \\
\hline & Rejection from friends & 9 & 30 \\
\hline & Alcohol dependency & 2 & 6.7 \\
\hline
\end{tabular}

*response doesn't add up to $100 \%$ due to multiple responses for single question.

\subsection{Factors Associated with Sexual Violence}

Factors associated with sexual violence in the current year in bivariate and multivariate analysis were: currently living with a boyfriend $(\mathrm{COR}=5.9,95 \%$ CI 1.9-18.6), alcohol drinking $(\mathrm{COR}=7.9,95 \%$ CI $2.58-24.63)$, having a friend who drink alcohol $(\mathrm{COR}=4.2,95 \%$ CI 1.37-12.7), and experiencing physical violence in the current year $(\mathrm{COR}=4.2$, 95\% CI 1.13-15.49). The multivariate analysis also showed that female students who are currently living with their boyfriend, $(\mathrm{AOR}=4.9,95 \%$ CI 1.02-23.78) and alcohol drinking ( $\mathrm{AOR}=7.3,95 \% \mathrm{CI}$ 1.24-42.76) were associated with sexual violence in the current year (Table 6).

Table 6. Bivariate and multivariate regression analysis for factors associated with sexual violence in the current year among female students of Menkorer high school in Debre Markos town, Northwest Ethiopia, 2014.

\begin{tabular}{|c|c|c|c|c|c|c|}
\hline \multirow{2}{*}{ Variables } & & \multicolumn{2}{|c|}{ Sexual violence this year } & \multirow{2}{*}{$\operatorname{COR}(95 \% \mathrm{CI})$} & \multirow{2}{*}{$\operatorname{AOR}(95 \% C I)$} & \multirow{2}{*}{ P-value } \\
\hline & & No & Yes & & & \\
\hline \multirow{3}{*}{$\begin{array}{l}\text { Currently married or live with } \\
\text { boyfriend }\end{array}$} & Yes married & $9(90)$ & $1(10)$ & $1.46(0.16,13.56)$ & $0.53(0.02,13.31)$ & 0.697 \\
\hline & Yes boy friend & $20(69)$ & $9(31)$ & $5.9(1.9,18.6)$ & $4.9(1.02,23.78)$ & 0.047 \\
\hline & No & $79(92.9)$ & $6(7.1)$ & 1 & 1 & \\
\hline \multirow{2}{*}{ Alcohol drinking } & Ever drunk & 28 & 12 & $7.9(2.58,24.63)$ & $7.3(1.24,42.76)$ & 0.028 \\
\hline & Never drunk & 80 & 4 & 1 & 1 & \\
\hline $\begin{array}{l}\text { Have a friend who drink } \\
\text { alcohol }\end{array}$ & Yes & 17 & 7 & $4.2(1.37,12.7)$ & $1.48(0.19,10.99)$ & 0.703 \\
\hline \multirow{2}{*}{ Physical violence this year } & No & 53 & 3 & 1 & 1 & \\
\hline & Yes & 55 & 13 & $4.2(1.13,15.49)$ & $3.08(0.53,17.88)$ & 0.21 \\
\hline
\end{tabular}

\subsection{Gender Based Violence}

The prevalence of life time Gender based violence (physical or/and sexual violence) and during the current academic year was $84(67.7 \%)$ and $72(57.3 \%)$ respectively. The bivariate analysis showed that current educational performance of good and above and average as reported by the respondents $(\mathrm{COR}=0.06,95 \% \mathrm{CI} \quad 0.007-0.58)$, and $(\mathrm{COR}=0.09,95 \%$ CI 0.01-0.73) when compared with students who have poor educational status, witness of violence as a child $(\mathrm{COR}=2.5,95 \% \mathrm{CI} 1.2-5.24)$, never 
drinking alcohol $(\mathrm{COR}=0.32,95 \% \mathrm{CI} 0.14-0.73)$. But, the multivariate analysis showed that factors associated with gender based violence among female students were current educational status of good and above $(\mathrm{AOR}=0.09,95 \% \mathrm{CI}$ $0.009-0.88)$, and never drinking alcohol $(\mathrm{AOR}=0.38,95 \% \mathrm{CI}$ 0.15-0.93) (Table 7).

Table 7. Bivariate and multivariate regression analysis for factors associated with Gender based violence in the current year among female students of Menkorer high school in Debre Markos town, Northwest Ethiopia, 2014.

\begin{tabular}{|c|c|c|c|c|c|c|}
\hline \multirow{2}{*}{ Variables } & & \multicolumn{2}{|c|}{ Gender based violence } & \multirow{2}{*}{$\operatorname{COR}(95 \% \mathrm{CI})$} & \multirow{2}{*}{$\operatorname{AOR}(95 \% C I)$} & \multirow{2}{*}{ P-value } \\
\hline & & No & Yes & & & \\
\hline \multirow{3}{*}{$\begin{array}{l}\text { Current Educational } \\
\text { status }\end{array}$} & Good \& above & $11(55)$ & $9(45)$ & $0.06(0.007,0.58)$ & $0.09(0.009,0.88)$ & 0.039 \\
\hline & Average & $41(45.6)$ & $49(54.4)$ & $0.09(0.01,0.73)$ & $0.12(0.02,1.04)$ & 0.054 \\
\hline & Poor & $1(7.1)$ & $13(92.9)$ & 1 & 1 & \\
\hline \multirow{2}{*}{$\begin{array}{l}\text { Witness of violence as } \\
\text { a child }\end{array}$} & Yes & $18(31)$ & $40(69)$ & $2.5(1.2,5.24)$ & $2.07(0.91,4.72)$ & 0.083 \\
\hline & No & $35(53)$ & $31(47)$ & 1 & 1 & \\
\hline Alcohol drinking & Ever drunk & $10(25)$ & $30(75)$ & 1 & 1 & \\
\hline
\end{tabular}

\section{Discussion}

The current study assessed the prevalence of gender base violence and associated factors among female students of Menkorer high school in Debre Markos town. Accordingly the prevalence of life time physical, and sexual violence was found to be $66.1 \%$ and $24.2 \%$. In addition, the prevalence of physical and sexual violence in the current year was found to be $54.8 \%$ and $12.9 \%$. Other similar studies conducted among college female students of Mekelle town showed that, the prevalence of life time physical and sexual violence was $46.3 \%$ and $45.4 \%$, and the prevalence of current physical and sexual violence was $26.4 \%$ and $28.1 \%$ respectively. Possible reason for such difference among the two studies could be due to the difference in socio demographic characteristics and the difference in the study population, the study in Mekelle town included female student from college, while the current study included high school students (9).

Another study conducted on sexual violence victimization among female secondary school students in Eastern Ethiopia showed that $68 \%$ of study participants experienced at least one occasion of sexual violence, in which $25 \%$ is due to sexual coercion (10). This finding is in comparison with the finding of current study, in which the prevalence of current sexual violence was $28.1 \%$.

A study conducted in Nigeria also showed that the prevalence of physical violence was $26.9 \%$ and that of sexual violence was $12.1 \%$ (11). This finding is relatively lower than the finding of the current study. The difference could be explained by a difference in socio demographic characteristics and the fact that the study in Nigeria included both male and female respondents while the current study only included young girls.

The life time and current prevalence of gender based violence among high school female students in the current study area was found to be $67.7 \%$ and $57.3 \%$ respectively. A study conducted in woredas surrounding Bahir Dar town, Burayuworeda, Bakoworeda and Gulele sub city of Addis Ababa found high levels of GBV. The highest prevalence was found in Bakoworeda with a prevalence of $100 \%$ and the lowest was found in Addis Ababa with prevalence of $90 \%$ (2). The high level of GBV in these areas when compared with the current finding could be due to the reason that the current study only assessed physical and sexual violence while the previous study also included domestic violence, and other forms of GBV.

Similar study conducted among female university students in northern Nigeria showed that the overall prevalence of GBV was $58.8 \%$, which is in comparable with the current finding (12).

This study also assessed factors associated with current physical violence, sexual violence and gender based violence. Factors associated with current physical violence were being urban resident, and witnessing of violence as a child. Urban resident students were almost five times more likely to experience physical violence than rural residents. This could be due to a reason that female students in urban areas start to have sexual partner/ or boyfriend and to drink alcohol early than their counterparts in the rural area, which may predispose them to several forms of violence as evidenced from other studies $(9,10,13)$.

The other factors associated with physical violence among female students were witnessing violence as a child. Young girls who witnessed violence as a child were almost four times more likely to experience physical violence than their counterparts. Similar findings were also observed in a study conducted among female college students of Mekelle town (9). Possible explanation for this could be the possible low level of parental control among young women who have violent family, and the fact that witnessing such violence from their family may result in developing a belief that violence is a normal condition, and this may expose them to fail to report oral threatening and may later expose them to gender based violence.

Sexual violence in the current year was significantly associated with relationship status and alcohol drinking. High school girls who have a boyfriend were almost six times more likely to had forceful sexual intercourse. This could be due to a reason that young girls who have a boyfriend are at increase vulnerability to be exposed for a violent behavior of their boyfriend. A study conducted in Eastern Ethiopia showed that women who have multiple sexual partners are more likely to be a victim of sexual violence since they may be willing even for unwanted sexual intercourse (10).

Female who drink alcohol were more than seven times 
more likely to experience sexual violence than those who didn't alcohol. This could be due to the relation between alcohol drinking and sexual violence, which is the effect of alcohol use on the occurrence of violence, specifically sexual violence. This finding is also supported by findings from Eastern Ethiopia, Mekelle, Cape Town, Nigeria and China (9$11,13,14)$. Similar finding was also observed in a study conducted in Mekelle town (9),

Gender based violence (physical and/or sexual violence) was also further analyzed for possible association with the independent variables. Accordingly, current educational performance of respondents, and alcohol drinking were found to have significant association with GBV. Respondents with current educational status of good and above were less likely to be a victim of gender based violence by $9 \%$ when compared with students who have poor educational status. This finding is similar with a study conducted in Mekelle town which showed that $37 \%$ of respondents who experienced rape reported they had poor academic achievement (9).

In addition respondents who never drank alcohol were less likely to experience GBV than those drank alcohol. Similar findings were also observed in the above mentioned studies.

The common consequences of physical violence among participants were disgusting people, $40 \%$, poor school achievement $29.3 \%$, school failure $14.6 \%$, and withdrawal from school $14.6 \%$. The most common individual who committed physical violence were family members, $47.6 \%$, followed by students $34.5 \%$, teacher, $20.7 \%$, and boyfriend/or husband $15.9 \%$.

The consequences of sexual violence was categorized in to the physical, psychological and social consequences. The physical consequences of forced sex as reported by the respondents were: injury around the genitalia, unusual vaginal bleeding, pregnancy, and swelling around the genitalia each accounting $33.3 \%, 20 \%, 16.7 \%$ and $13.3 \%$ respectively. The common forms of psychological consequences of forced sex were fear $66.7 \%$, anxiety $63.3 \%$ and depression $63.3 \%$. And the common social consequences and risk behaviors due to forced sex were withdrawal from school; $63.3 \%$ and poor academic achievement $53.3 \%$. Similar findings were also observed in a study conducted in Mekelle town; which showed that the common problems of rape were fear, 77\%; hopelessness, $42 \%$; and suicidal attempt, $10 \%(9)$.

\section{Conclusion}

This study found that gender based violence is still a common problem among high school female students. The prevalence of current and life time physical and sexual violence among female students was high. In addition more than two third of female students and more than half of female students reported that they have experienced GBV in their life time and in the current year respectively. Factors associated with current physical violence were being urban resident, and witnessing violence as a child. Factors associated with current sexual violence were having a boyfriend and alcohol drinking. In addition alcohol drinking was found to be a risk for gender based violence, while good school achievement among female students was found to be protective against gender based violence. The common consequences of physical violence were disgusting people, poor school achievement and withdrawal from school, and respondents have also reported several physical, psychological and social consequences of sexual violence.

\section{Recommendation}

Based on the above findings, we would like to recommend the following points:

- School based services like awareness creation on the social and economic consequences of GBV, the physical and psychological consequences, the impact of GBV on the perpetrator and on the society should be done for both male and female students.

- Students who experience GBV should be immediately identified and should be enrolled in school and/or community based support programs. Immediate Sexual Transmitted Infections (STIs)/like HIV/AIDS risk assessment should be done, and immediate provision of emergency contraceptives should be given for those who experience sexual violence to prevent unwanted pregnancy and its complications.

- Perpetrators should be identified and necessary punishment should be commenced, and laws related with GBV should be strengthen, and community awareness on the laws should be created through the available Medias of communication.

- Further studies in a larger scale including male students should also be done for better understanding of the contributing factors for GBV.

\section{Acknowledgement}

We would like to thank to Debre Markos University, College of Medicine and Health science, for the ethical clearance to conduct this study. We also like to thank to Menkorer high school administrators, and teachers for their cooperation and students for participating and completing the questionnaire.

\section{References}

[1] Population council. Sexual and gender based violence in Africa: Literature review. February 2008.

[2] CARE Ethiopia. The Status of Gender Based Violence and Related Servicesin Four Woredas (Woredas surrounding Bahir Dar town, Burayuworeda, Bakoworeda and Gulele Sub-city of Addis Ababa), February 2008

[3] Gender Studies Institute, Kabul University with Cooperation of UNDP and UNESCO. Gender based violence, a study of three universities in Afghanistan, March 2010. 
[4] Auerbach, J., Bryam, E. \& S. Kandathil. 2005. Gender-Based Violence and HIV among Women: Assessing the Evidence. Amfar: Issue Brief No. 3, June 2005.

[5] Iliyasu Z, Abubakar IS, Aliyu MH, Galadancihs and Salihu HM. Prevalence and Correlates of Gender-based Violence among Female University Students in Northern Nigeria. African Journal of Reproductive Health September 2011; 15(3): 111-119.

[6] Worku A, and Addisie M. sexual violence among female high school students in Debark, North West Ethiopia. East African Medical Journal, February 2002, vol. 79 No. 2 : 96-99.

[7] Debre Markos history and demographic. [Internet]. [Cited 2014 March 12]. Available from: www.en.wikipedia.org/wiki/Debre_Marqos

[8] Fitaw Y, Haddis K, Million F, et al. Gender Based Violence among High School Students in North West Ethiopia. Ethiopian Medical Journal: January 2005; 43(4):215-221.

[9] Yaynshet G/Yohannes. Prevalence and factors related to gender based violence among female students of higher learning institutions in Mekelle town, Tigray, Northern Ethiopia. [Unpublished thesis]. June 2007, Addis Ababa University.
[10] Alemayehu Belachew Bekele. Marcel A. G. van Aken, Judith Semon Dubas. Sexual Violence Victimization among Female Secondary School Students in Eastern Ethiopia. Violence and Victims, Volume 26, Number 5, 2011. pp 608-630.

[11] Oladepo O1, Yusuf $\mathrm{OB} * 2$ and Arulogun OS. Factors Influencing Gender Based Violence among Men and Women in Selected States in Nigeria. African Journal of Reproductive Health December 2011; 15(4): 78-86.

[12] Zubairu Iliyasu1, Isa S Abubakar1, Muktar H Aliyu2, Hadiza $\mathrm{S}$ Galadanci3 and Hamisu $M$ Salihu. Prevalence and Correlates of Gender-based Violence among Female University Students in Northern Nigeria. African Journal of Reproductive Health September 2011; 15(3): pp. 111-119.

[13] Naeemah Abrahams, Rachel Jewkes, Margaret Hoffman, Ria Laubsher. Sexual violence against intimate partners in Cape Town: prevalence and risk factors reported by men. Bulletin of the world health organization 2004; 82:330-337.

[14] William L. Parish, Tianfu Wang, Edward O. Laumann, Suiming Pan and Ye Luo. Intimate Partner Violence in China: National Prevalence, Risk Factors and Associated Health Problems. International Family Planning Perspectives, Vol. 30, No. 4, Gender-Based Violence and Reproductive Health (Dec., 2004), pp. 174-181. 